\title{
Os ataques neoliberais à previdência social pública brasileira, seus efeitos sobre o serviço social e as contribuições da assessoria via extensão universitária
}

\section{The neoliberal attacks on the Brazilian public social security, its effects on social work and the contributions of the advisory via university extension}

\author{
Silvina V. Galizia ${ }^{a}$
}

\begin{abstract}
Resumo
Este trabalho é resultado de desdobramentos gerados pelo Projeto de Extensão: "Assessoria via Extensão Universitária" (ESS-UFRJINSS), nas suas dimensões constitutivas de ensino, pesquisa e extensão. Centramo-nos na relação existente entre as sucessivas "contrarreformas" da previdência social (de 1998 até hoje) -que reduzem benefícios, dificultam o acesso a esses, precarizam a estrutura institucional, reduzem ou eliminam direitos conquistados pelos trabalhadores historicamente-, e as alterações impostas ao exercício profissional do assistente social inserido nesse espaço ocupacional, que enfraquecem a profissão e aprofundam a sua subordinação aos objetivos institucionais. Em seguida, trabalhamos os desafios que o "Projeto de Assessoria via Extensão Universitária" enfrenta para defender e fortalecer o projeto profissional destacando especialmente o exercício da autonomia relativa e a legitimidade institucional e social da profissão.
\end{abstract}

Palavras-chave: contrarreforma da previdência social, serviço social, assessoria/extensão universitária, autonomia relativa, legitimidade profissional.

\begin{abstract}
This work is the result of developments generated by the Extension Project: "University Extension Advisory" (ESS-UFRJ-INSS), in its constitutive dimensions of teaching, research and extension. We focus on the relationship between the successive social welfare "counter-reforms" (from 1998 to date) - which reduce benefits, hinder access to them, precarious institutional structure, reduce or eliminate rights historically earned by workers - and changes imposed on the professional practice of the social worker inserted in this occupational space, which weaken the profession and deepen its
\end{abstract}

a Universidade Federal do Rio de Janeiro, Escola de Serviço Social, Brasil.

Correspondencia a: silvinagalizia@gmail.com

Recibido:

30 julio 2019

Aceptado:

28 noviembre 2019

Artículo publicado en acceso abierto bajo la Licencia

Creative Commons.

(c) (i)

Cita:

Galizia, S. (2019). Os ataques neoliberais à previdência social pública brasileira, seus efeitos sobre o serviço social e as contribuições da ássessoria via extensão universitária. Kera Yvoty: reflexiones sobre la cuestión social, 4, 65-76. 
Galizia, S. Os ataques neoliberais à previdência social pública brasileira, seus efeitos sobre o serviço social e as contribuições da assessoria via extensão universitária.

subordination to institutional goals. We then address the challenges that the "University Extension Advisory Project" faces in defending and strengthening the professional project, with particular emphasis on the exercise of relative autonomy and the institutional and social legitimacy of the profession.

Keywords: social security counter-reform, social work, university advisory/ extension, relative autonomy, professional legitimacy.

\section{Apresentação}

O Projeto "Assessoria via extensão Universitária" (ESS/UFRJ-INSS), assessora assistentes sociais que atuam em diversas instituições públicas. Aqui, abordaremos o trabalho de assessoria aos assistentes sociais de Agências de três Gerências Executivas (GEX) do Instituto Nacional de Seguro Social (INSS) que se constituem como espaços sócio ocupacionais de Serviço Social. A assessoria na ESS/UFRJ configurase como uma atividade de extensão que envolve as dimensões de ensino, pesquisa e extensão, tripé indissociável da formação profissional onde a universidade pública afirma a sua função social.

É possível constatar que, ao passo que vão se concretizando as contrarreformas da previdência social, desmontando a política social de proteção previdenciária e o próprio Instituto Nacional de Seguro Social (INSS), se sucederam até hoje, várias modificações no exercício profissional, aprofundando a subordinação das atribuições e competências ${ }^{1}$ profissionais às requisições institucionais. Isto se expressa na mudança ou eliminação de instrumentos e rotinas de trabalho, no afastamento da profissão de práticas relacionadas à defesa de direitos sociais previdenciários junto aos segurados, na precarização das condições materiais e humanas de trabalho, tentativas de desqualificação

1 Atribuições profissionais são as ações de responsabilidade exclusiva através de um cargo ou função, são funções privativas. Na Lei de Regulamentação Profissional (Lei 8662/93) aparecem como prerrogativas privativas. Expressam o perfil, projeto e formação profissional. Competência profissional é a capacidade de dar certa resolutividade a determinados assuntos sem exclusividade. teórica e técnica, enfraquecimento éticopolítico profissional e até a exclusão Serviço Social do sistema previdenciário e, ao mesmo tempo, incorporando e reorientando funções que o aproximam de ações relacionadas com programas da área da assistência (Benefício de Prestação Continuada - $\mathrm{BPC}^{2}$ ), da previdência social/ saúde do trabalhador como o Programa de Reabilitação Profissional'3, Aposentadoria para a Pessoa com Deficiência, entre outros.

O objetivo deste trabalho é expor de que forma entendemos esta constatação através do Projeto de Extensão e como lidamos com os ataques à profissão e com o seu necessário fortalecimento através da assessoria.

Portanto, uma vez reconhecidas as várias e constantes alterações profissionais, trabalharemos a partir de uma das inquietações permanentes do conjunto de sujeitos envolvidos no Projeto assistentes sociais, docentes, técnicas e estudantes-, a necessidade de estabelecer ações que qualifiquem permanentemente à profissão, teórica metodológica, técnica e politicamente, desde seu projeto éticopolítico profissional, projeto de formação e compromisso com a ampliação da cidadania no atual cenário de redução de programas, benefícios, auxílios, direitos sociais e limitação do exercício profissional.

Entendemos o Serviço Social como

\footnotetext{
2 O Benefício de Prestação Continuada (BPC) é um benefício assistencial, inserido na Lei Orgânica da Assistência Social, mas operacionalizado pelo Instituto Nacional de Seguro Social (INSS) desde sua implantação em 1996.

3 Inclusive, através de cargo genérico como o de Orientador Profissional com função de Assistente Social.
} 
uma profissão definida na divisão sócio técnica do trabalho e determinada pelos fenômenos da realidade mais amplos externos a ela. Para compreendermos as mudanças atuais no espaço sócio ocupacional do assistente social na Previdência Social pública, devemos partir de uma análise, por um lado, das largas transformações sofridas pelo Estado e pela área da política social previdenciária nas últimas três décadas e, por outro, de que as particularidades e tensões do trabalho do assistente social acontecem na relação entre a defesa do projeto ético-político profissional e a necessária, mas relativa, obediência às requisições institucionais. (Iamamoto, 2009).

Para tanto, apresentamos primeiro, as implicações que o processo de reformulação das funções do Estado e "contrarreformas" do sistema de previdência social público brasileiro trazem para a atuação do Serviço Social no espaço sócio ocupacional da Previdência Social pública, focando desde meados da década de 1990.

Em segundo lugar, apontamos as repercussões que as "contrarreformas" da Previdência Social trazem para o Serviço Social desde a constatação de que, cada vez mais profundamente, a profissão encontra suas ações subordinadas às demandas institucionais que limitam e abalam o seu protagonismo relativo.

Com o terceiro ponto, avançamos na descrição e sentido das intervenções que o projeto de "Assessoria via Extensão Universitária" concebeu para ampliar e fortalecer as ações da profissão no interior da instituição previdenciária (INSS).

Trabalhamos com análises teórico críticas sobre a "contrarreforma" do Estado, desmistificadoras da crise e insustentabilidade do sistema de previdência social público e sobre a trajetória do Serviço Social no interior da área definido desde a contradição expressa pela relação de forças existente em cada conjuntura; pesquisa documental; resultados parciais da pesquisa sobre perfil profissional (assistentes sociais participantes do projeto 2016-2018), sob responsabilidade do Projeto de Extensão "Assessoria via Extensão Universitária UFRJ-INSS"; observação participante e trabalho extensionista dos integrantes do Projeto, junto ao conjunto de Assistentes Sociais lotadas nas Agências da Previdência Social (APS) vinculadas às Gerências Centro, Caxias e Norte do INSS do Rio de Janeiro desde 2013 até a atualidade. No Projeto conseguimos acompanhar as mudanças ocorridas nas atribuições e competências profissionais e requisições institucionais desde então.

A extensão é papel essencial da universidade e a assessoria é uma atividade profissional, competência e atribuição privativa do assistente social. O Projeto de "Assessoria via Extensão Universitária" vincula então, o âmbito acadêmico (estudantes, técnicos e professores) e os profissionais de campo (assistentes sociais). Nele se expressa a relação entre fundamentos ético-políticos, teóricometodológicos e técnicos da profissão e a realidade social na qual todos os sujeitos sociais estamos envolvidos através da conformação de campos de estágio (assistentes sociais supervisores e alunos), grupos de pesquisa (estudantes, técnicos e professores) e ações de extensão (todos os integrantes). Assim, pretendemos efetivar: 1) uma formação crítica e propositiva, voltada para a comunidade universitária e externa; 2) fortalecimento, ao mesmo tempo, das unidades acadêmicas e os espaços sócio ocupacionais públicos num movimento de ida e volta de conhecimento; 3) ampliação e fortalecimento das ações profissionais em vista da autonomia profissional e ampliação da cidadania dos segurados.

\section{Contrarreforma do sistema de Previdência Social público brasileiro}

Desde meados do século XX, diversos capitais, sob domínio das finanças, para recuperar e manter a sua lucratividade, consideram espaços públicos (serviços 
Galizia, S. Os ataques neoliberais à previdência social pública brasileira, seus efeitos sobre o serviço social e as contribuições da assessoria via extensão universitária.

sociais) e recursos públicos (fundo público), como parte das áreas a serem exploradas e apropriadas por eles.

No Brasil, especialmente desde meados dos anos $1990^{4}$, os sucessivos governos neoliberais estimulam a privatização e mercantilização dos bens e serviços de satisfação de necessidades sociais, incentivando o seu deslocamento para a sociedade civil (famílias, indivíduos ou entidades sem fins lucrativos), ou para setores empresariais lucrativos.

A "contrarreforma" 5 neoliberal do Estado e da Seguridade Social (desde início da década de 1990), redefine as políticas sociais instituídas pela Constituição de 1988. Implementa estratégias que aprofundam a precarização dos sistemas nacionais ou permanentes de saúde e educação públicos e aumenta a dificuldade de acesso às proteções previdenciárias. Ao mesmo tempo, liberam e ampliam a entrada de capitais privados nas áreas de políticas social e subsidiam e apoiam às empresas privadas lucrativas nas áreas de seguros de saúde, educação e pensões privadas para trabalhadores melhor posicionados no mercado de trabalho. Isto se complementa com a sustentação de programas assistenciais mínimos para trabalhadores informais, desempregados e/ou precarizados. Ademais, renovam-se formas de apropriação privada do fundo público que financia as políticas sociais de proteção e se reestabelece o princípio de individualização da responsabilidade pela proteção social das famílias (Werneck, 1998; Mota, 1995; Iamamoto, 2009).

Esta reformulação sustenta-se político e ideologicamente com estratégias

4 O incentivo público estatal à presença de setores privados (lucrativos e não lucrativos) no Brasil data dos anos de 1970, nas áreas da saúde (com o aumento dos planos privados de saúde), pensões (fundos de pensões fechados empresariais) e educação. Mota, A. (1995).

5 "Contrarreforma" entendida como o período neoliberal onde são tomadas diversas medidas governamentais que restringem, limitam e/ ou eliminam direitos sociais historicamente conquistados pelos diversos setores de trabalhadores. que criam um amplo consenso social e legitimação governamental apresentando falsos argumentos para aprovar as reformas através da grande mídia, a cooptação de lideranças político sociais, ações repressivas e/ou uso da violência, num cenário de constante enfraquecimento, desmobilização, passivação de conflitos ${ }^{6}$ e necessária reorganização política dos trabalhadores e da sociedade civil (Iamamoto, 2009; Coutinho, 2010; Mota, 2008, Neves, 2005).

A reestruturação da política de previdência social completa a sua quarta fase atualmente. Começa em 1998, no governo Cardoso (FHC) com a EC n ${ }^{\circ} 20$; segue em $2003\left(\mathrm{EC}^{\circ} 47\right)$, durante o governo Lula da Silva; a terceira fase se completa em 2015 com a chamada "mini-reforma" da Previdência no governo Dilma Russeff; a quarta fase começa em 2016 com a PEC $n^{\circ} 247 / 16$, não aprovada durante o governo golpista de Temer e atualmente, 2019, com a PEC nº 06/19, aprovada em outubro de 2019 sob o governo Bolsonaro.

Em seu conjunto, todas as reformas, sustentam uma linha constante de reorganização dos princípios básicos e a gestão previdenciária, diminuindo benefícios, serviços e auxílios nos Regimes Geral e Próprio; dificultando, cada vez mais, o acesso dos segurados a eles e restringindo os direitos dos contribuintes. Este conjunto de novas regras se completa com mudanças administrativas do sistema previdenciário, incorporações precárias $\left(2005^{-2015}\right)^{7}$ de novas categorias de trabalhadores ao sistema e restrição de benefícios através

\footnotetext{
6 Através de medidas de desindicalização, repressão às manifestações contra as políticas neoliberais e até a criminalização de movimentos sociais reivindicativos.

7 Pelo menos, em três categorias de trabalhadores: revisão dos benefícios dos Empregados Domésticos (Lei Complementar 150/15), incorporação das Donas de Casa através da EC n 47/05 e do Microempreendedor Individual (MEI) com a Lei Complementar $n^{\circ} 128 / 08$. Todos eles condicionados à renda e com redução de contribuições e, por tanto, de benefícios.
} 
de um teto (atualmente de $\mathrm{R} \$ 5 \cdot 839,45^{8}$ ). Assim, vai se concretizando a precarização da área da política pública de previdência e incentivando a ampliação do sistema de Previdência Complementar (fundos de pensões privados abertos e fechados) ${ }^{9}$, reafirmando a noção de "proteção" individual através de investimentos financeiros que permitem a apropriação privada direta da renda dos trabalhadores.

Como principais mediações
profissionais, as políticas e programas sociais são instrumentos indissociáveis do Serviço Social, portanto, o que acontece no âmbito desses repercutirá diretamente na ação profissional.

\section{Trajetória e caracterização do Serviço Social previdenciário}

Desde a sua conformação, o espaço sócio ocupacional do serviço social na Previdência Social passa por constantes transformações. Tendo como referência Iamamoto (2009), o Serviço Social é produto da combinação do processo histórico de construção dos diversos projetos profissionais com as ações de diversas forças sociais fora e dentro desse espaço.

O serviço social na previdência social surge na década de 1940 e mantem uma trajetória constante de avanços, ampliação e retrocessos da intervenção profissional desde então. Inclusive, neste campo de atuação, o serviço social impulsionou a própria profissionalização no país.

No interior da Previdência, a profissão desenvolveu, primeiramente, uma intervenção tradicional, controladora dos trabalhadores segurados; passou por ações humanistas e assistencialistas (inscritas no Plano Básico de Ação de 1972); e práticas funcionalistas, tecnocráticas e adaptadoras dos trabalhadores individuais

8 Equivale a US 1.463,52 (1 US americano igual a 3,99 Real brasileiro. 03/11/19. 20:01. Fonte UTC).

9 Como por exemplo, a criação do Funpresp (Fundação Previdenciária Complementar do Servidor Público Federal) em 1998 e instalado em 2013. à dinâmica societária (no Plano Básico de Ação de 1978).

Somente, em 1991, a lei 8.213 (Plano de Benefícios da Previdência), no seu Art. 88, definiu para o Serviço Social:

Compete ao Serviço Social esclarecer junto aos beneficiários seus direitos sociais e os meios de exercê-los e estabelecer conjuntamente com eles o processo de solução dos problemas que emergirem da sua relação com a Previdência Social, tanto no âmbito interno da instituição como na dinâmica da sociedade. (Lei 8.213/91, art. 88)

Determinaram-se também as competências do Serviço Social na Previdência como um direito dos trabalhadores e da população usuária na sua relação com a política previdenciária. Nesse mesmo momento, o Serviço Social, junto com a perícia médica, reabilitação profissional e seguro social integrou o Projeto 24, uma elaboração de novos "modelos conceituais" que foram base para a criação, em 1994, da Matriz TeóricoMetodológica do Serviço Social no INSS. Com a Matriz, a profissão ingressa reconhecidamente no campo da ampliação dos direitos sociais, participação dos usuários na gestão das políticas sociais, construção de instrumentos condicentes com essa nova direção e defesa da previdência pública, reestruturando as suas atividades profissionais a partir de princípios democráticos e da compreensão da realidade social como fundamentos para organizar a ação (INSS, 1995). Ela traz uma direção e intencionalidade teóricometodológica e política crítica portanto, é qualificada como uma ruptura com a orientação funcionalista que caracterizava o Serviço Social até então.

Contudo, estes avanços vão de encontro com as medidas de "contrarreforma" gerencial do Estado, da Seguridade Social e da área da Previdência Social, processadas praticamente na 
Galizia, S. Os ataques neoliberais à previdência social pública brasileira, seus efeitos sobre o serviço social e as contribuições da assessoria via extensão universitária.

mesma época e que tendem a reorganizar e precarizar a estrutura e gestão previdenciárias.

Estes fenômenos, como já trabalhados no primeiro item, alteram o espaço ocupacional e repercutem diretamente sobre as ações do Serviço Social previdenciário nos seus campos constitutivos: afetando as suas dimensões teórico-metodológicas, ético políticas, técnico-operacionais e as condições do assistente social como trabalhador assalariado. Vejamos.

Desde início dos anos 2000 até hoje, as mudanças sofridas pelo Serviço Social no interior da Previdência Social poderiam ser divididas em três mentos. Entendemos os dois primeiros, de acordo com Cartaxo - Reis Cabral e Braga (2007), como desconstrução e reconstrução da profissão, os quais se configuram, de forma contraditória, como expressões da tensa relação entre as requisições institucionais e resistências profissionais aos diferentes objetivos da política previdenciária.

Concretamente, no primeiro momento (entre finais dos anos 1990 e 2007), por um lado, o Serviço Social sofreu sérias restrições às suas ações, que vão desde a tentativa de extinção da profissão $0^{10}$, até a mudança de cargo para os profissionais de Serviço Social (da "condição de prestação de serviços previdenciários” e "atividade complementar" " para "atividade auxiliar"12), e a perda de espaço na estrutura organizacional, onde excluiuse administrativamente o Serviço Social do organograma institucional. Em termos teórico-metodológicos, a afirmação do Serviço Social como "atividade auxiliar" tende a reeditar a concepção adaptadora e psicossocial contida no Plano Básico de Ação de 1978. Restringiu-se o alcance de instrumentos técnicos como o parecer social (em 2002), e houve sérias

10 Através da Medida Provisória n 1729/98.

11 Lei Orgânica da Previdência Social (1960). Art. N $52 / 60$.

12 Decreto 3048/99. Art. $\mathrm{N}^{\circ} 161$. reduções orçamentárias ${ }^{13}$. Ademais, o reduzido quadro de profissionais, após demissões voluntárias em $1995^{14}$ e mais de duas décadas sem concurso público, comprometeu fortemente a existência da profissão no interior da estrutura da política previdenciária.

Como se afirma em Cartaxo - Reis Cabral e Braga (2007), estes processos foram, em parte, revertidos pela força de vários setores da sociedade e movimentos organizados dos assistentes sociais através das suas entidades representativas (CFESS, CRESS), docentes universitários, representações parlamentares, et outros, que, em 2003, levaram a retomar as competências e atribuições privativas do cargo de assistente social no INSS lotados nas Divisões e Serviços de Benefícios, mas ainda com dispersão de profissionais e restrição de instrumentos técnicos.

Contudo, por outro lado e contraditoriamente, em 2004, como ações do Programa de Previdência Social Básica do Ministério da Previdência Social, a atuação do assistente social encontrava-se em expansão pois, ademais das competências estabelecidas no artigo $\mathrm{n}^{\circ} 88$ da lei 8213/91, o assistente social participaria do Programa de Educação Previdenciária (PEP) e do Programa de Reabilitação Profissional (Reabilita). Mas cabe esclarecer que os responsáveis pelo Programa Reabilita, até hoje, possuem o cargo de "Orientadores Profissionais", ocupado tanto por assistentes sociais como por outros profissionais como psicólogos, terapeutas ocupacionais, sociólogos, etc., o que desvaloriza a especificidade do saber da intervenção profissional do assistente social por se caracterizar como um cargo genérico.

Desde 2007, início do segundo

\footnotetext{
13 Suspensão dos recursos materiais que viabilizavam a entrada dos usuários aos benefícios previdenciários como vales transporte, acesso à documentação, entre outros.

14 Programa de demissões voluntarias para servidores públicos existente desde o governo.
} 
momento de alterações nas requisições profissionais, adiciona-se a realização das "avaliações sociais ${ }^{15}$ para acesso ao Benefício de Prestação Continuada (BPC $\left.{ }^{16}\right)$ ".

Para a realização desta ação profissional, depois de muitas negociações dos Conselhos Profissionais (CRESS/ CFESS) com parlamentares e representantes do INSS, em 2008, ingressaram por concurso público em todo o país, ainda que insuficientes, 900 "analistas de seguro social”, com formação em Serviço Social, com a atribuição específica de intervir na concessão e revisão do BPC, que só poderá ser gestionado a partir da avaliação social do assistente social.

Já, a partir de 2013, devido ao escoamento das demandas das avaliações sociais do BPC, o Serviço Social reaproximase às demandas previdenciárias, porém, priorizando o Programa de Reabilitação Profissional e a Avaliação de Aposentadoria para Pessoa com Deficiência ${ }^{17}$, ações que se configuram como requisições institucionais e que formam parte das competências profissionais.

Entendemos estas mudanças na atuação profissional como uma reconstrução do Serviço Social, ainda que não de acordo com os princípios defendidos pela Matriz Teórico-Metodológica, uma vez que, nem o atendimento previdenciário, nem procedimentos teórico-metodológicos inscritos na Matriz, se constituiu como prioritários nas ações profissionais.

Por tanto, é possível afirmar que, no decorrer dos anos 2000, por um lado, processaram-se ações que tendem à

15 As avaliações serão baseadas na Classificação Internacional de Funcionalidade, Incapacidade e Saúde (CIF), conforme decreto $n^{\circ}$ 6217/2007, em consonância com a Lei de Regulamentação Profissional (8662/93), e também mais tarde disposto em alteração da Lei Orgânica de Assistência Social (LOAS, 2003), em 2013.

16 A habilitação e concessão do BPC sempre foram realizadas por servidores administrativos, atuais técnicos do seguro social no INSS, lotados na área de benefícios.

17 Lei Complementar no 142/13. Regulamentou o art. 201, § 1o, da Constituição Federal de 1988. desconstrução da profissão, por outro lado, emergem novas e inéditas requisições e demandas, exigência de reedição de habilidades e competências numa ampliação clara de atividades solicitadas ao Serviço Social, especialmente com a sua direta contribuição com o programa de avaliação da deficiência e do grau de incapacidade das pessoas com deficiência no BPC e com todas as atividades a esse associadas como a socialização de informações, orientação de usuários, articulações das instituições públicas, garantia da multidisciplinariedade, entre outras, que compreendem atribuições privativas dos assistentes sociais, conforme estabelece a Lei de Regulamentação Profissional n 8662/93, reconstruindo-a.

Atualmente, aparecem novas limitações institucionais às ações profissionais, desrespeitando, restringindo ou ignorando as atribuições privativas e competências profissionais e sobrepondo requisições institucionais. Podemos entender estas alterações como um terceiro momento onde observamos uma tendência à descaracterização da profissão, configurando inclusive, uma nova tentativa de desmonte da profissão. Resumidamente, isto expressa-se em:

1) Implementação de estratégias institucionais que afastam o atendimento do usuário das Agências e, portanto, do atendimento presencial do usuário através da criação do sistema "INSS Digital"18, que instala $O$ atendimento exclusivamente virtual, impedindo ademais, a socialização das informações; diminuição do tempo para avaliação social para 30 minutos; restrição de instrumentos como (informes, visitas e pareceres sociais) e de recursos materiais (passagens para usuários e deslocamento para profissionais).

2) Requisições institucionais, mesmo que não normatizadas formalmente, vinculadas a ações puramente administrativas como habilitação de

18 Através dos Memorandos $n^{\circ} 13$ de 26/10/17 DIRSAT/ INSS e n²5 /DIRBEN/INSS. 
Galizia, S. Os ataques neoliberais à previdência social pública brasileira, seus efeitos sobre o serviço social e as contribuições da assessoria via extensão universitária.

benefícios, o que significa a reunião e controle de documentos e confrontação de informações no banco de dados dos usuários. Estas funções são entendidas como estrita e meramente fiscalizadoras, o que pode ser caracterizando como desvio de função já que são requisições incompatíveis com as atribuições privativas da profissão.

3) Mais uma vez, o INSS esvaziou a representação hierárquica da profissão. Primeiro, na Superintendência Regional de Belo Horizonte (2016) e posteriormente, na Direção Geral em Brasília (2018). Como consequência disto, o Serviço Social se encontra subordinado a chefias de outras áreas profissionais, especialmente a representações médicas. Assim, se prevê uma limitação da autonomia e especificidade da profissão e um aumento da dificuldade de elaboração de planos de trabalho específicos para o exercício profissional no nível regional e nacional.

4) Constante exigência de rotinas relacionadas ao cumprimento de metas vinculadas a ganhos salariais coletivos e de multifunções através da acumulação de atendimentos em diversos programas simultaneamente ${ }^{19}$, numa conjuntura onde se expressa uma histórica carência de profissionais (sucessivas aposentadorias sem renovação de vagas concursadas) e, portanto, acumulação de funções. Isto é complementado com um extremo controle tecnológico do exercício profissional através de sofisticados sistemas informacionais.

5) Vivencia-se atualmente a renovação concreta das ameaças de extinção da profissão do organograma institucional.

Este conjunto de requisições enfraquecem a profissão na sua relação com os usuários e companheiros de trabalho o que afeta a sua legitimidade interna e social.

Entretanto, sabendo que a profissão se define no movimento contraditório das relações entre as diversas forças sociais,

19 Como por exemplo, atendimentos a usuários do Programa de Reabilitação Profissional e previdenciários ou estes últimos e avaliações sociais do BPC. ela renova sua tradicional luta política através de esforços de organização da categoria nos Encontros Estaduais e Nacionais anuais, representações nacionais e regionais e participação e protagonismo nas representações sindicais.

\section{O trabalho profissional como expressão da contradição social. Assessoria Professional na Extensão Universitária}

Uma das chaves de análise mais apropriadas para refletir sobre esta temática encontra-se nas ponderações de Iamamoto (1992, 2004, 2007, 2009, 2012), que dizem respeitoàsmudançasnosespaçosocupacionais e o exercício da relativa autonomia dos profissionais de Serviço Social.

Por um lado, está claro que o assistente social, trabalhador assalariado e, fundamentalmente, responsável pela implementação de políticas e programas sociais no interior das instituições, trabalha na tensão existente entre a autonomia relativa e a condição de assalariado (Iamamoto, 2004) ou entre o projeto profissional e as demandas institucionais (Iamamoto, 2009).

Atualmente, no interior do processo de contrarreforma da previdência, predominam os interesses institucionais por sobre os do projeto profissional crítico. Isto tensiona a luta pela hegemonia em favor dos interesses das classes dominantes, fato que certamente condiciona e limita a autonomia profissional.

Contudo, por outro lado, sabemos que, o espaço profissional do Serviço Social se configura como um produto histórico e está condicionado por: a) o nível de luta pela hegemonia das classes fundamentais e suas alianças e b) pelo tipo de respostas profissionais técnicas e práticas com conteúdo político dadas pela categoria profissional. Estas respostas são criadas a partir da capacidade de análise da realidade, capacitação técnica e política em consonância com as conjunturas vividas. (Iamamoto, 2009). 
O trabalho de assessoria profissional através da extensão universitária se insere desde a observação conjunta da realidade e da organização das respostas dadas a ela.

Portanto, nestes últimos anos, entre 2016 e 2018, período de ataques ainda mais duros ao sistema previdenciário público brasileiro e às ações privativas do Serviço Social, identificamos como o grande desafio do projeto a exaltação e defesa das atribuições e competências profissionais.

A dinâmica do trabalho da assessoria profissional

Em primeiro lugar, o trabalho de assessoria consiste em identificar, conjuntamente (todos os integrantes do processo), as áreas que devem ser analisadas e, na sequência, as temáticas a serem abordadas. Isto se realiza através de diversos encontros: reuniões ampliadas, exercícios de análise conjuntural, visualização de possibilidades concreta de trabalho, entre outras.

O trabalho de reconhecimento começou em 2016 com, entre outras, a Pesquisa de Perfil Profissional onde, entre outros pontos, abordamos a dimensão de lugar ocupado pela profissão no interior da instituição, as atuais requisições institucionais, condições materiais de trabalho profissional e continuou com o trabalho de Sistematização da Prática Profissional.

O resultado da Sistematização expõe, corrobora e legitima concretamente as vivencias cotidianas expressas pelos profissionais de serviço social no decorrer dos anos de trabalho no Projeto de Assessoria.

Há três áreas do trabalho dos assistentes sociais que podem ser visualizadas como comprometidas na atual conjuntura ${ }^{20}$. Essas podem ser

20 Os dados que seguem foram levantados através da pesquisa "Perfil profissional" elaborada em 2016 e sistematizada em 2018, já apresentada em três Encontros de Pesquisa e Extensão Universitárias apresentadas como: 1) aumento da dificuldade do acesso aos benefícios e serviços por parte dos usuários ante os ataques que a contrarreforma da política de previdência vem sofrendo, 2) precarização das condições de trabalho (materiais e humanas) do assistente social enquanto trabalhador assalariado, 3) limitações às ações privativas e instrumentos de trabalho do assistente social.

A partir daqui, nos encontros de planejamento, a equipe discute, avalia, cria e executa estratégias e ações que contribuam para o fortalecimento da profissão no interior da instituição, especialmente com os colegas de equipes (profissionais de outras áreas profissionais e técnicos administrativos).

Ante as observações e discussões de trabalho, a equipe planeja e organiza conjuntamente as ações estratégicas relacionando as práticas profissionais a partir da análise teórico metodológica da profissão. Assim, organizam-se as ações que serão desenvolvidas pela equipe de profissionais do INSS, alunos, técnicos e professores da ESS-UFRJ. Estas são:

$\left.1^{\circ}\right)$ Reuniões com coordenações de serviço social das três Gerências (Centro, Caxias, Norte), com as Responsáveis Técnicas (RT's), para planejamento e agenda de trabalho;

$2^{\circ}$ ) Reuniões semestrais ampliadas, incluindo assistentes sociais assessoradas (os), professoras, técnicas, extensionistas, estudantes, pesquisadoras, com pauta de análise eavaliação da realidade institucional e ações profissionais;

$\left.3^{\circ}\right)$ Eventos semestrais abertos à comunidade da Escola de Serviço

\footnotetext{
(Siac 2016, 2017 e 2018), e para os próprios assistentes sociais participantes do projeto (2018). Nela expressase fundamentalmente a falta de reconhecimento profissional por parte do conjunto de funcionários técnico-administrativos e outros profissionais do INSS, deslegitimidade do trabalho profissional, limitações no trabalho profissional, falta de recursos materiais e condições de trabalho, desvios de funções, limitações nos recursos materiais para segurados, afastamento do assistente social do atendimento direto com usuário, negação de instrumentos de trabalho profissional.
} 
Galizia, S. Os ataques neoliberais à previdência social pública brasileira, seus efeitos sobre o serviço social e as contribuições da assessoria via extensão universitária.

Social da UFRJ e demais profissionais do INSS com o tratamento de temáticas relacionadas com as diversas conjunturas estabelecidas no decorrer dos últimos anos: a "contrarreforma" das Políticas Sociais e da Previdência; o Serviço Social na Previdência Social; os benefícios previdenciários; a sistematização da prática profissional; os fundamentos do Serviço Social; a sua instrumentalidade; atribuições e competências profissionais; as dimensão ético-política do Serviço Social;

$4^{\circ}$ Elaboração de planilha: "Sistematização da Prática Profissional" para o reconhecimento do conjunto de ações e funções exercidas pelos profissionais de Serviço Social no interior da Instituição (requisições, atribuições e competências);

$5^{\circ}$ ) Identificação das problemáticas possíveis de serem abordadas através de projeto profissional no interior do espaço ocupacional;

$\left.6^{\circ}\right)$ Capacitação continuada através do Curso de Aperfeiçoamento sobre "Fundamentos e elaboração do Projeto Profissional" na ESS-UFRJ, para os profissionais envolvidos no projeto.

Todas as ações possuem um elo condutor que se entende como o reconhecimento claro de todas as ações privativas exercidas, a elaboração e fortalecimento do projeto profissional no interior do projeto ético político ea primazia da defesa da autonomia profissional, respeito às atribuições e competências profissionais em processos de trabalho democráticos e a defesa dos direitos dos trabalhadores segurados.

\section{Conclusão}

Serviço Social e políticas sociais são inseparáveis. As transformações contemporâneas que redefinem as primeiras influenciam diretamente às ações dos assistentes sociais. Atualmente, a restrição das políticas sociais públicas se coloca na contramão da noção de ampliação de direitos sociais existente no Projeto Ético-Político profissional expressando, tanto novas requisições institucionais conservadoras, quanto abrindo possibilidades para outras ações de intervenção do assistente social.

Porém, apesar dos interesses profissionais estarem em desvantagem ou enfraquecidos na relação de forças no terreno institucional, a contrarreforma do Estado e da Previdência Social coloca para o Assistente Social o desafio de observar com atenção as novas requisições institucionais e sustentar a relativa autonomia que direcione o nosso trabalho por um caminho distinto aos dos nossos empregadores.

Para assegurar a autonomia do profissional, nesta conjuntura adversa, devemos trabalhar coletivamente valores éticos que orientam a profissão, as competências teórico-metodológicas, as suas bases legais, entre outras dimensões que materializam o projeto profissional associado às forças sociais comprometidas com a democratização da vida em sociedade (Iamamoto, 2009).

Ademais, a relativa autonomia pode se dirigir para ancorar politicamente o trabalho profissional com direção a atender as demandas dos usuários mesmo contrárias as definições institucionais.

Para isto, pesemos num profissional que não reduza a visão das suas práticas profissionais a um movimento unilateral, exclusivamente intervindo sob as exigências institucionais, cujas ações só possam expressar a submissão ao poder institucional. No mesmo processo podemos observar, contraditoriamente, requisições institucionais que restringem e condicionam cada vez mais o acesso aos benefícios previdenciários, intensificam e precarizam o trabalho do assistente social, limitam o exercício profissional, e ações capazes de reeditar possibilidades de intervir potencialmente na promoção da articulação das políticas sociais (previdência e assistência), orientação dos usuários e socialização da informação, participação na realização da avaliação social em vários programas (BPC, Reabilitação Profissional e Aposentadoria para Pessoa com Deficiência), e influenciar 
nos pareceres sociais junto a outros profissionais e técnicos da perícia médica.

Para avançar neste desafio, precisa-se de um aprofundamento do entendimento teórico-analítico da realidade, dos fundamentos que sustentam as políticas sociais e da atual configuração do esquema de política social brasileiro, das possibilidades da própria intervenção técnico-operativa, da análise das condições matérias dos usuários e da correlação de forças no interior das Agências e do próprio INSS.

Estes elementos possibilitarão ao assistente social perceber o espaço e as ações interventivas como tensas, contraditórias e potenciais, devendo procurar constantemente qualificação acadêmica, defesa das suas funções privativas e alianças técnico-políticas com profissionais e técnicos que compartilhem os mesmos princípios de defesa da Seguridade Social pública e ampliação de acesso aos direitos sociais.

O trabalho da assessoria profissional através da extensão universitária, contribui direta econtinuamente para estes processos.

\section{Referências Bibliográficas}

Brasil. Lei 8.213/91, Dispõe sobre os Planos de Benefícios da Previdência Social e dá outras providências.

Brasil. Ministério da Previdência Social. (2008). Edital no 1, de o6 de novembro de 2008 - Concurso público para provimento de vagas no cargo de Analista do Seguro Social. Diário [da] Oficial República Federativa do Brasil. http://www.jusbrasil.com.br/ diarios/890801/dou-secao-3-10-112008-pg-90

CFESS. ABEPSS. (2009). Serviço Social: direitos sociais e competências profissionais. Brasília: Cfess, ABEPSS, UnB.

Conselho Federal de Serviço Social. (20og). Código de Ética Profissional dos
Assistentes Sociais, 1993. Coletânea de Leis e Resoluções (vol I). Rio de Janeiro: Conselho Regional de Serviço Social.

Coutinho, C. N. (2010). A hegemonia da pequena política. In C. Rizek, F. Oliveira, R. Braga (Eds.), Hegemonia às avessas: Economia, política e cultura na era da servidão financeira. São Paulo: Boitempo.

Iamamoto, M. V. (1992). Renovação e conservadorismo no Serviço Social. Ensaios críticos. São Paulo: Cortez.

Iamamoto, M. (2004). A questão social no capitalismo. Brasilia: Temporalis.

Iamamoto, M. V. (2007). Serviço Social em tempo de capital fetiche. Capital financeiro, trabalho e questão social. São Paulo: Cortez.

Iamamoto, M. V. (2009). Os espaços sócios ocupacionais do Assistente Social. In Serviço Social: direitos sociais $e$ competências profissionais. BrasíliaDF: CEFESS/ABEPSS.

Iamamoto, M. V. (2012). Projeto profissional, espaços ocupacionais e trabalho do assistente social na atualidade in Atribuições privativas do/a assistente social em questão. Brasília: CFESS,

Instituto Nacional de Seguro Social, INSS. (1995). Matriz Teórico-Metodológica do Serviço Social na Previdência Social. Brasília: Ministério da Previdência e Assistência Social.

Mota, A. E. (1995). A centralidade da assistência social na Seguridade Social brasileira nos anos 2000, In Mota, A. E. (Ed.), O mito da assistência social: ensaios sobre estado, política e sociedade ( $2^{\mathrm{a}}$ ed., p. 133-146). São Paulo: Cortez Editora.

Mota, A. E. (1995). Cultura da crise e seguridade social. São Paulo: Cortez.

Neves, L. M. W. (2005). A nova pedagogia da hegemonia. Estratégias do capital para educar o consenso. São Paulo: Xamã. 
Reis Cabral, M. A., \& Braga, L. (2007). O Serviço Social na Previdência. Trajetórias, projetos profissionais e saberes. São Paulo: Cortez.
Werneck, V. (1998). As armas secretas que abateram a seguridade social. In I Lesbaupin (Ed.), O desmonte da Nação. Balanço do governo FHC (3ㅜㅡㄴ ed.). Petrópolis: Vozes.

\section{Sobre la Autora}

Silvina V. Galizia

Assistente Social e doutora em Serviço Social. Professora Associada III do Departamento de Política Social e Serviço Social Aplicado da Escola de Serviço Social da Universidade Federal do Rio de Janeiro. Coordenadora do Núcleo de Pesquisa sobre políticas sociais e de proteção social na América do Sul. 